\title{
Resenha: Memória e Sociedade: Lembranças de Velho
}

\author{
Fernanda Lopes Rêgo Soares* \\ Bosi, Ecléa. Memória e Sociedade: Lembranças de Velhos. 14. ed. São Paulo: \\ Companhia das Letras, 2007.
}

Como citar esse artigo. Soares,

F.L.R. Resenha: Memória e Sociedade: Lembranças de Velho. Revista Mosaico. 2018 Jan./Jun.; 09 (1): 50-52.

\begin{abstract}
Resumo
Esta resenha tem por objetivo apresentar a obra "Memória e Sociedade: Lembranças de Velhos" de Éclea Bosi que analisa o discurso de idosos através da reconstrução da sua memória familiar e grupal, como também sua inserção na sociedade, utilizando teóricos que trabalham com a temática História, Memória e Sociedade.

Palavras-Chave: História; Sociedade; Biografias
\end{abstract}

\begin{abstract}
This review aims to present the work "Memória e Sociedade: Lembranças de Velhos” by Éclea Bosi, who analyzes the discourse of the elderly through the reconstruction of their family and group memory, as well as their insertion in society, using theorists who work on the theme History, Memory and Society..

Keywords: History; Society; Biographies.
\end{abstract}

Ecléa Bosi, escritora brasileira nascida em São Paulo, professora de psicologia social na Universidade de São Paulo e militante de ecologia, é autora de variadas obras, dentre elas "Cultura de Massa" e "Cultura Popular".

As narrativas do livro retratam o apanhado de memórias de velhos, uma camada da população subjugada pela dependência e opressão marcada pela sociedade capitalista assinalada pela exploração do trabalho servil impedindo o velho de exercer sua função social. Logo, trata-se de uma memória social, uma psicologia do oprimido, o qual revela de como a diferença de seus trabalhos é determinante na produção de lembranças.

As entrevistas foram realizadas com pessoas de idade superior a setenta anos e com residência na cidade de São Paulo, cujo principal objetivo foi registrar a voz, a vida e o pensamento desses indivíduos que dedicaram suas vidas ao trabalho. Abrange uma memória pessoal, familiar e grupal, onde apresenta o modo de ser do indivíduo e da cultura o qual está inserido, cujo foco central é valorizar suas lembranças perpetuando a história de suas vidas.

O recurso utilizado como método de abordagem foi a criação de um vínculo de amizade e confiança com os recordadores, fruto de uma busca de compreensão empática da própria vida revelada pelo sujeito, cujas memórias foram contadas oralmente.

Visando um melhor entendimento e embasamento teórico para subsidiar sua pesquisa, utilizou autores tais como Bergson, Halbwachs, Bartlett e Stern apresentando suas reflexões acerca da memória.

No capítulo 1 intitulado Memória - Sonho e Memória - Trabalho, a autora apresenta a reflexão a respeito do fenômeno da memória em si que marca sua relação com a vida social e para isto utiliza o filósofo da vida psicológica, Henri Bergson, que retratou a fenomenologia da lembrança em sua obra intitulada Matière et Mémoire, cujo foco central da discussão é o tempo e memória. Discorre acerca da percepção e como a mesma define ações e reações do sujeito, uma representação simbólica descrita de forma detalhada de como funciona este fenômeno. O pensador questiona-se sobre a passagem da percepção das coisas para o nível da consciência. Narra-nos em seguida: "Na realidade, não há percepção que não esteja impregnada de lembranças" (BERGSON, 1959 apud BOSI, 2007, p. 46). A lembrança está impregnada pelas representações as quais atribuem

Afiliação dos autores: Graduanda do Curso de Pedagogia da Universidade de Vassouras. Bolsista de Iniciação Científica da FUSVE/USS, no Projeto de Pesquisa "Trajetórias de Vida nas Vozes de Educadores Maricaenses".

*fernandalrsoares@gmail.com 
à memória uma função decisiva no processo psicológico.

O Método Introspectivo de Begson nos possibilita compreender a memória como força subjetiva composta por representações seja do passado ou do presente, o nosso conhecimento e apreensão da realidade. Faz a distinção de memória-hábito, que está relacionada com nossa prática do dia a dia (adestramento cultural) vida ativa, da imagem-lembrança (vida contemplativa), que emerge da consciência um momento ou uma situação única vivenciada em sua vida. Em seu estudo, busca compreender a correlação entre a conservação do passado e a sua articulação com o presente, logo, a junção de memória e percepção que sobre as formas de lembranças sobrevive de forma consciente (no tempo presente), mesmo que em estado inconsciente.

Maurice Halbwachs principal estudioso das relações entre memória e história pública, amplia os estudos de Émile Durkheim sobre as funções que as representações e ideias dos indivíduos exercem no seu grupo de convívio e na sociedade como um todo. Uma preexistência, um predomínio social sobre o individual altera os fenômenos psicológicos tais como, percepção, consciência e memória. Seu enfoque central não é a memória, mas os quadros sociais da memória, onde as relações não estão limitadas ao campo da pessoa, mas em relação à realidade interpessoal com as instituições sociais a qual faz parte. Sendo assim, a memória do indivíduo estaria intrinsecamente subordinada ao seu relacionamento com a família, com a classe social, Igreja, profissão, ou seja, grupos de convivência e referência a qual pertença. Portanto, liga a memória da pessoa à memória do grupo, relacionada à memória coletiva, a tradição de cada sociedade.

Charles Bartlett corrobora com as ideias de Maurice Halbwachs, pois ambos fundamenta os quadros sociais no processo que conduz a lembrança. A vida atual é inseparável ao processo de reconstrução do passado admitindo a existência contínua da criação social de novos símbolos sofridos pelas influências extras grupais. A memória estaria dependente desse ininterrupto processo de que só "fica" o que significa, ora intacto, ora eminentemente alterado. A construção social da memória estaria ligada ao grupo onde se trabalha em conjunto, pois tende a criação de esquemas coerentes da narração e interpretação das situações ocorridas, verdadeiros "universos do discurso e significado," que servirão de alicerce seguro quanto à história e veracidade dos acontecimentos. Bartlett apresenta a distinção entre matéria de recordação (o que se lembra) e o modo da recordação (como se lembra). A matéria estaria relacionada ao interesse social que o fato lembrado tem para o sujeito, já o modo estaria ligado à psicologia da personalidade (temperamento e caráter). Nesse particular, a teoria de Halbwachs estudioso dos níveis sociais de memória, se opõe por ater-se somente as relações vividas pelo sujeito.
William Stern (1957), citado por Bosi (2007, p. 67) analista da memória com visão puramente psicológica, assim como Bergson, considera que o sujeito conservaria suas percepções em estado ou "período latente", ausentes da consciência desperta, entretanto, poderiam reaflorar por motivos variados. O sujeito conserva as imagens do passado, mas poderiam alterá-las em função de influências concretas do seu desenvolvimento. A memória seria a conservação ou reestruturação do passado, onde resulta a flexibilidade da mesma. Stern admite a suposição da existência de uma memória "pura" mantida no inconsciente, aliada a suposição de serem reelaboradas pelos valores do presente se aproximando das teorias de Bartlett e Halbwachs.

Diante de tantas reflexões trazidas, podemos pensar como o fenômeno da memória pode ocorrer de forma única e particular em cada indivíduo. Isto se evidencia que a narração de suas próprias experiências de vida é o modo mais assertivo de descrever e fazer a memória.

No capítulo 2 intitulado Tempo de Lembrar, a autora busca compreender a função da memória da velhice. Os velhos assumem caráter essencial na vida e na formação do indivíduo, visto que eternizam memórias e lembranças, sejam elas pessoais, de um tempo, lugar, pessoas e objetos. A criança apreende assim o passado; mergulha suas raízes através da história vivida por pessoas de mais idade que fizeram parte de sua socialização.

Simone de Beauvoir tece reflexões acerca da velhice em relação às mudanças históricas decorridas pela sociedade e sua divisão de classes ocasionando a ruptura nas relações sejam elas entre os homens, seja na relação com os homens e a natureza. Em nossa sociedade, a velhice é marcada por grandes opressões e exigências sejam elas do grupo familiar a que pertença, seja da própria burocracia e justiça as quais o idoso encontrase submetido. A sociedade industrial caracterizada por produção, agilidade e lucro, oprime a velhice por considerar essa classe sem força para o trabalho.

A memória como função social é descrita como o vínculo com outra época, com a consciência de ter vivenciado tantos desafios e conquistas que traz para o idoso a alegria, satisfação e oportunidade de mostrar sua competência. Isto gera um sentimento de pertencimento, onde sua vida enche-se de valor a espera de ouvidos atentos às suas narrativas. O diálogo com o idoso é uma experiência profunda, repleta de nostalgia que traz suas lembranças, sejam elas de sentimentos, emoções, situações e pessoas que enriquecem aquele que ouve, oportunizando a recuperação de um tempo, que outrora fora tão significativo para o sujeito "velho" que lembra.

$\mathrm{Na}$ era digital, onde a tecnologia está tão presente no cotidiano das pessoas, percebe-se a escassez da arte 
de trocar experiências e de ouvir histórias, onde nessa era da informação imediata, a busca pela sabedoria é substituída pela mera opinião, muitas vezes superficial e sem reflexão. Portanto, ouvir uma narração que não está centrada nos livros, mas centrada na experiência pessoal do indivíduo, ocasiona em experiência transformadora para aquele que ouve.

No capítulo 3 intitulado Lembranças, a autora transcreve o resultado de suas entrevistas com os oito sujeitos entrevistados. Retrata a biografia individual de cada entrevistado, onde cada qual expõe suas vivências pessoais e profissionais. Histórias singulares de memórias de trabalho, recordações de infância, festejos, hábitos simples na cidade de São Paulo, acontecimentos, perdas, tristezas, alegrias, paisagens, pontos históricos, dentre outros.

No capítulo 4 intitulado A Substância Social da Memória, a autora apresenta uma análise dos resultados embasados nas teorias citadas no princípio desta resenha.

Muitas recordações absorvidas não são nossas, mas relatadas por nossos familiares e futuramente relembradas por nós. Leva-nos a compreender que a memória, a lembrança, e a recordação, são compartilhadas e construídas em conjunto, asseverando o fator social preponderante em sua construção. A recordação está ligada a significação, algo que de certa forma teve um real valor, algo subjetivo. Para Halbwachs cada memória individual é um ponto de vista sobre a memória coletiva. O grupo é visto como um suporte da memória e se nos identificamos com ele e fazemos nosso o seu passado. É preciso estar sempre trocando, comunicando e recebendo impressões de forma que as lembranças sejam preservadas.

Discorre acerca da reflexão a respeito da divisão social do tempo que está além da cronologia das horas contadas no relógio, mas algo profundamente subjetivo e repleto de significado para o sujeito. Aqui a dimensão do tempo pode ser sentida e percebida de forma singular por cada indivíduo dependendo da situação que está vivendo. A expressão "meu tempo", utilizada pelos que recordam, é vista como o tempo pertencente a ele, onde se considerava um indivíduo inteiro, protagonista de sua história. Na construção da memória familiar é importante a interação com outros grupos, de forma que se possa reagrupar lembranças de outros espaços sociais na construção de recordações.

Discorre acerca dos espaços da memória, no qual a casa materna é um cenário presente nas autobiografias, onde está contida os momentos mais importantes da infância, assim como os objetos biográficos que é algo descrito com profundo significado na vida do sujeito.

Apresenta as duas dimensões do trabalho: sua repercussão no tempo subjetivo do sujeito entrevistado seja quanto à realidade objetiva do sistema capitalista. Conclui que a memória do trabalho é o sentido, é a justificação de toda uma biografia.

As narrativas do livro contribuem de forma significativa para a valorização das lembranças dos "velhos", na história individual de cada sujeito, onde favorece a aprendizagem daquele que ouve e contribui para uma melhor compreensão do tempo e dos ensinamentos trazidos pelas experiências vivenciadas e compartilhadas, permitindo assim que esses indivíduos cumpram sua função social na sociedade a qual estão inseridos.

\section{Referência}

BOSI, Ecléa. Memória e Sociedade: Lembranças de Velhos. 14.ed. São Paulo: Companhia das Letras , 2007. 